Volume and Issues Obtainable at Center for Sustainability Research and Consultancy
www.globalcsrc.org
Journal of Business and Social Review in Emerging Economies
ISSN: 2519-089X; (Online) 2519-0326
Volume 2: Issue 1 June 2016
ᄃSRᄃ

\title{
The Comparison of Vocabulary Learning Strategies among High School Students in Three Southern Border Provinces of Thailand and Malaysia
}

\author{
1*Pratya Binmadnee \\ ${ }^{1}$ Assistant Professor, Faculty of Liberal Arts and Social Sciences, Fatoni University Thailand \\ benseventy@gmail.com
}

\begin{tabular}{l}
\hline ARTICLE DETAILS \\
\hline History \\
Revised format: May 2016 \\
Available Online: June 2016
\end{tabular}

Keywords
Vocabulary learning
Strategies,
Reading ability
Three Southern Border
Provinces

JEL Classification: L19, Y50

\begin{abstract}
Objective: The purposes of this paper are to 1) To compare the vocabulary learning strategy in English reading of upper - secondary students who have the different reading ability in three southern border provinces of Thailand and Malaysia. 2) To know the vocabulary learning strategy in English reading of upper - secondary students who have the different reading ability in three southern border provinces of Thailand and Malaysia.

Methodology: To analyze the data of the research, Analysis of Variance (ANOVA) and the Scheffe method was used to compare the pair of difference of the vocabulary strategy questionnaire which was administered to 197 high school students.

Results: The findings reveal that there were relations between the level of reading ability and the country toward the usage of the vocabulary learning strategy. And both students from three southern border provinces of Thailand and Malaysia who were different in reading ability possessed the different vocabulary learning strategy.

Implication: This research encourages English learners in three southernmost areas of Thailand to realize the importance English usages, especially in understanding of the vocabulary learning strategies to comprehend the various English texts. The efficient key to be successful in reading skill is teaching them to know more vocabulary because knowing the limited vocabulary gives the direct effects to the English efficiency. This study can be considered as the key of Thai students in the areas are able to learn the vocabulary learning strategies to enhance themselves for being the qualified member of ASEAN.
\end{abstract}

(C) 2016 The authors, under a Creative Commons AttributionNonCommercial 4.0

\section{Introduction}

In this competitive era, no one denies that vocabulary acquisition plays the important role in English studying and teaching. David Wilkins (as cited in Subon, 2013) said that "Without grammar very little

*Corresponding author's email address: benseventy@gmail.com

Recommended citation: Binmadnee, P. (2016). The Comparison of Vocabulary Learning Strategies among High School Students in Three Southern Border Provinces of Thailand and Malaysia. Journal of Business and Social Review in Emerging Economies, 2 (I), 61-70. DOI: https://doi.org/10.26710/jbsee.v2i1.19 
can be conveyed, without vocabulary nothing can be conveyed". Thus, the vocabulary skill is needed for efficient English learners, especially in reading skill which was considered as one of the most essential skills for the learners of English to achieve not only learning a language, but also acquiring knowledge from any content areas (Subon, 2013). In addition, Laufer (2010) agreed that reading was critical to the academic achievement of second language and it's necessary for readers to have at least 5,000 vocabulary to understand the general English articles (Laufer, 2010). It can be clearly seen that students who have the limited vocabulary knowledge will face difficulties in all four language skills - listening, speaking, reading and writing.

Due to the poor English vocabulary among students in Thailand, several studies mentioned that they lack of reading practice. Thantawan et al (2008) studied reading ability of students from Prince of Songkhla University, Pattani Campus and found that the limitation of vocabulary knowledge can be seen by most of students from the faculty of Communication Science, Islamic Studies, and Social Sciences who were from Islamic - Private schools. Suknantapong et al (2002) concluded that the poorest skill in reading ability of students from Humanities and Social Sciences was inference and guessing the meaning from context clues. Moreover, Kaewklom's also mentioned that vocabulary was the problem in English reading (Kaewklom, 2002).

Despite reading being an essential skill, students in Thailand, especially in three southern borders gained a low score on their reading test. According to the result of the Ordinary National Educational Testing (O-NET), the National Institute of Educational Testing Service indicates that, students in Narathiwat, Pattani and Yala have had the lowest score in English on their O-Net test in Thailand since 2008. They have been ranked of $75-77$ out of the 77 provinces in Thailand. In the year of 2009, they had achieved only 23.31,19.53, and 18.98 respectively, with a total score of 100 . In the latest year of 2013 O-NET Score, the result of English efficiency was still under the standard and couldn't achieve the goal of language learning achievement. The average score from three southern border province students was only 19.22 from 100. Students from Yala got only 18.00, Pattani students got 17.99, and Narathiwat students got 17.93 (National Institute of Educational Testing Service, 2014).

The problem mentioned above showed that Thai English learners don't know the vocabulary learning strategies in order to improve their reading skill. Therefore, to resolve the mentioned problems, the way to learn the vocabulary strategies from the top ASEAN country as Malaysia which was successful in English efficiency can be the important tool to develop Thai learners in English study. Many Malaysian students were continuously provided the efficient vocabulary learning strategies as studied by Frankie. He found that students in Form 6 which was prepared for university level had the various efficient vocabulary learning strategies so they didn't have any problems in reading English when they studied in the higher level. Also, Azeedad and Ghazali's research found that the vocabulary learning strategies of University Putra Malaysia were efficient and be able to use the vocabulary in the various contexts because of their continuous learning from secondary level (Azeedad and Ghazali, 2011).

In the coming future of ASEAN community, English becomes more important and necessary. There are many proposed methods to resolve English problems of Thai learners, but the most important method in the view of the researcher is teaching them to know more vocabulary because knowing the limited vocabulary gives the direct effects to the English efficiency. The comparison of the vocabulary learning strategies of Malaysian upper secondary students can be considered as the key of Thai students, especially in three southern border provinces of Thailand are able to learn the vocabulary learning strategies to enhance themselves for being the qualified member of ASEAN. 


\section{Literature review}

\subsection{The Overview of Thai and Malaysian educational system}

The educational system of public schools in Malaysia is 6-3-2 pattern. The primary level contained six years study, the lower-secondary level contains three years of study, and in the upper-secondary level contained two years of study. In 2003, English was encouraged to be used as the instructional medium language for Sciences and Maths classes in grade 1, 7, and 10. But in 2009, the classes were allowed to use Bahasa Malaysia again since teachers were sufficiently proficient in English (ASEAN Secretariat, 2014).

Thai Education system consisted of 12 years free basic education with 6-3-3 patterns guaranteed by the Constitution. The primary level contained 6 years of study, the lower - secondary level contained three years of study, and the upper - secondary level contained three years of study. The basic education system has to be enrolled by students at the age of 6 . And likewise the southern provinces of Thailand, especially in three border provinces, namely Pattani, Yala, and Narathiwat, it was found that a significant percentage of students from three southern border provinces of Thailand had very limited proficiency in English. As they did not understand the content in English textbooks, these students performed badly in national tests, ranking the lowest in O-Net for the national university entrance examination (Thantawan et al.,2009).

\subsection{Vocabulary learning strategies}

As mentioned by Schmitt (1997), language learners used vocabulary learning strategies to acquire the new words in the second language study. Although there were some arguments in classifying the vocabulary learning strategies between Schmitt's taxonomy who believed in the classification of learning strategies suggested by Oxford (1990) and the extensive taxonomy of Cook and Mayor, It had also been confirmed that the vocabulary learning strategies students used, had a great impact on the success of their vocabulary learning (Schmitt, 1997).

There were different definitions of vocabulary learning strategies. As cited in Cravern (2013), language learning strategies focused on identifying lists of strategies and classified according to whether they were direct or indirect strategies (Cravern, 2013). In 1990, Oxford invented the strategy called the Strategy Inventory for Language Learning (SILL) which were divided into direct and indirect strategies. SILL strategy were divided into direct and indirect strategies. Direct strategies contained memory, cognitive and compensation strategies. While metacognitive, social and affective strategies were contained in indirect strategies (Oxford,1990). Macaro (2006) defined the concept in favor of listing essential characteristics and explained that language learning strategies were the relationship of the activities between language learning strategies and English proficiency to regulate students' own learning (Macaro, 2006). Moreover, there were some researchers, for instances, Schmitt, Griffiths, Nation, and Neilson also demonstrated and showed a relation between language learning strategy and English proficiency which was adopted from Oxford (1990).

Various researches proved that the usage of language learning strategies related to the success in second or foreign language learning. Cohen and Aphek found that 12 Hebrew students who were taught by making paired mnemonic associations to remember the vocabulary showed better results than those who did not (Cohen and Aphek, 1980). In addition, Subon studied the vocabulary learning strategies employed by form 6 Malaysian Students. The results revealed that the overall samples used a medium frequency of strategy. The most frequently used strategy by the students was guessing while the least was using the pocket dictionary. Also Azadeh and Ghazali studied ESL students in University Putra 
Malaysia about the type of vocabulary learning strategies. They found that most of students were eager to learn words in reading with dictionary. Medias were also used to learn new vocabulary, the strategies likes memory, determination, and metacognitive strategies were also applied the uses of new English words in their daily conversation (Azadeh and Ghazali, 2011).

There are some researches on vocabulary learning strategies in Thailand. Tinutda and Waraporn concluded from their study entitled "Vocabulary Learning Strategies Employed by Undergraduate Students and its Relationship to their Vocabulary Knowledge" that the most frequently strategies used was determination strategies, whereas the least often used strategies were social strategies (Tinutda and Waraporn, 2011). Suphawat (2011) found that three of the top five items were determination strategies while three of the bottom five items belong to the metacognitive category. It was also revealed that, in general, the students failed to employ each of these reported strategies as frequently as the degree they perceived them as useful in learning vocabulary. The study also identified four major factors contributing to the students' failure to use the strategies they considered useful: lack of practice, lack of motivation, lack of English proficiency, and complexity of word knowledge (Suphawat, 2011).

\section{Methodology}

\subsection{Subjects}

The research subjects were 197 high school students studying at three Southern Border Provinces of Thailand and The border states of Malaysia, obtained through the purposive random sampling. Subjects were divided into 48 high students, 76 medium students, and 73 low students based on their percentage of the reading test, see Table 1.

Table 1: Number of subjects and their English efficiency

\begin{tabular}{|c|c|c|c|c|c|c|c|}
\hline \multirow{3}{*}{$\begin{array}{l}\text { Class } \\
\text { Grade } 11\end{array}$} & \multicolumn{3}{|c|}{ Thailand } & \multirow{2}{*}{\multicolumn{2}{|c|}{ Class }} & \multicolumn{2}{|r|}{ Malaysia } \\
\hline & $\mathrm{N}$ & \multicolumn{2}{|c|}{ Percentage } & & & $\mathrm{N}$ & Percentage \\
\hline & 19 & \multicolumn{2}{|c|}{16.36} & \multicolumn{2}{|l|}{ Form 4} & - & - \\
\hline Grade 12 & 93 & \multicolumn{2}{|c|}{83.03} & Form 5 & & 85 & 100 \\
\hline \multicolumn{8}{|c|}{ Level of English Efficiency } \\
\hline \multicolumn{2}{|c|}{ Excellent } & \multicolumn{2}{|c|}{ Fair } & \multicolumn{4}{|c|}{ Poor } \\
\hline Thai & Malaysia & Thai & Malaysia & & Thai & & Malaysia \\
\hline 12.18 & 12.18 & 21.31 & 17.26 & & 23.35 & & 13.70 \\
\hline
\end{tabular}

\subsection{Research Instruments}

The instrument used in the data collection was the vocabulary learning strategies questionnaire adapted from Strategy Inventory for Language Learning (SILL), (Oxford,1990), and vocabulary acquisition of $\mathrm{Gu}$ and Johnson (1996). It is certainly true that the SILL is designed to investigate language learning strategies in general. However, it can be used to investigate vocabulary learning strategies, in particular. The students had to answer 36 item questions on their vocabulary- strategy use on a five-point Likert scale ranging from "never, rarely, sometimes, very often, and always. The questionnaire consists of two 
parts: (1) personal information about the participants and (2) questions about the differences between direct strategies and indirect strategies. Direct strategies contained three strategies which were memory strategies (with 2 techniques, perception and rehearsal techniques), cognitive strategies (with 3 techniques, management, dictionary, and sources), and compensation strategies with 2 techniques, encoding and guessing). Indirect strategies consisted of 1 technique, activation from metacognitive strategies.

\section{Results}

4.1 The result of the vocabulary learning strategies usage among Thai high school students and Malaysia high school students who have the different English efficiency

To investigate research objective 1 ( To compare the vocabulary learning strategy in English reading of upper - secondary students who have the different reading ability in three southern border provinces of Thailand and Malaysia.), two way analysis of variance was used as the descriptive statistics, see table 2.

Table 2 : Result of two way analysis

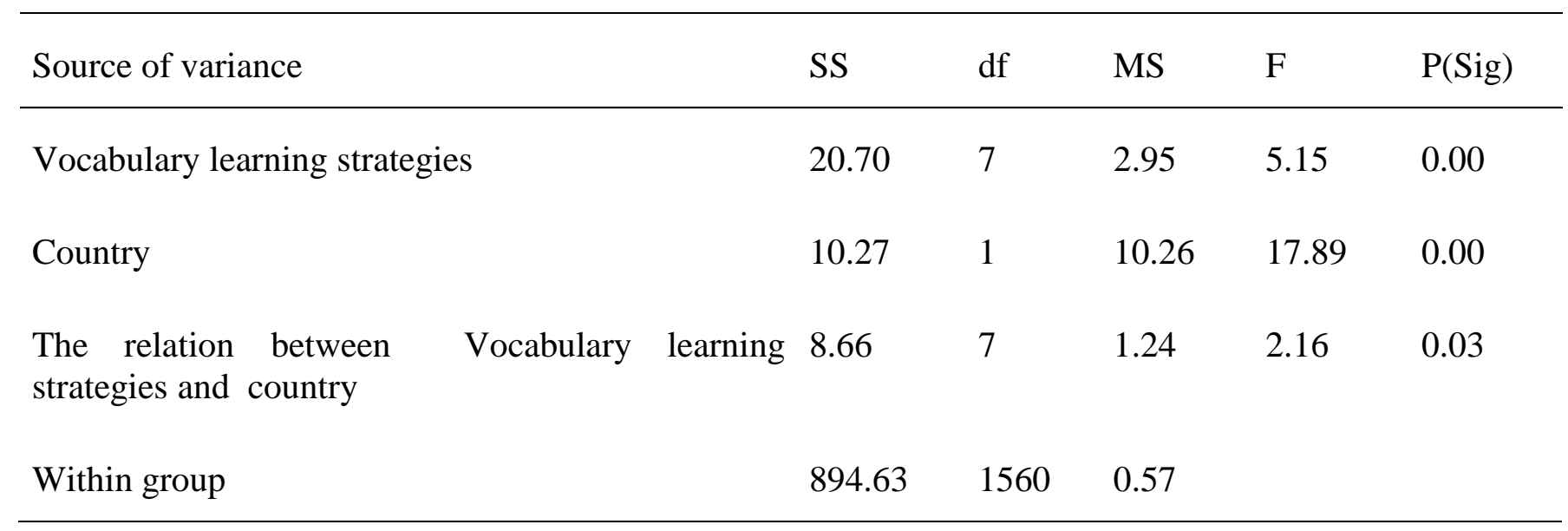


From table 2, the F- test value of vocabulary learning strategies was 5.15 with the significance of 0.00 . It could be explained that the different usage of vocabulary learning strategies affects the level of frequency in using vocabulary learning strategies. The F- test value of the country was 17.89 with the significance of 0.00 . It could be explained that the country affects the level of frequency in using vocabulary learning strategies. The F- test value of the relation between vocabulary learning strategies and country was 2.16 with the significance of 0.03 . It could be explained that the relation between vocabulary learning strategies and country affect the level of frequency in using vocabulary learning strategies. Therefore, it can be concluded that students from different countries affects the difference of using the vocabulary learning strategies, and if students use the different vocabulary learning strategies also affects the level of frequency average scores in using vocabulary learning strategies.

4.2 The result of the vocabulary learning strategies usage of Thai high school students who have the different English efficiency

To investigate this research objective, one- way analysis of variance was used as the descriptive statistics, see table 3 .

Table 3: Result of Thai vocabulary learning strategies

\begin{tabular}{llllll}
\hline Source of variance & Sum of Squares & df & Mean Square & F & Sig. \\
\hline Between group & 1.083 & 2 & .542 & 3.96 & .03 \\
Within group & 2.875 & 21 & .137 & & \\
Total & 3.958 & 23 & & \\
\hline
\end{tabular}

From the table, it could be explained that the level of reading ability toward the vocabulary learning strategies usage of Thai high school students who have the different English efficiency had the significant statistics with the level of 0.03 . It meant that the decision of usage the vocabulary learning strategies followed upon the reading ability. It could be concluded that between the different group of students (High, Medium, and Low) used different vocabulary learning strategies.

Then, the Scheffe Method was used to compare each pair difference of the vocabulary learning strategies usage of Thai high school students between high, medium, and low group as shown in table 4 .

Table 4: Result of Scheffe Method of Thai high school students

\begin{tabular}{|c|c|c|c|c|c|}
\hline \multirow[t]{2}{*}{ Level } & \multirow[t]{2}{*}{$\operatorname{Mean}(\bar{X})$} & \multicolumn{3}{|c|}{ Group } & \multirow[t]{2}{*}{ Sig } \\
\hline & & Low & Medium & High & \\
\hline Low & 3.0 & - & 0.12 & $0.50 *$ & 0.04 \\
\hline Medium & 3.12 & & - & 0.37 & \\
\hline High & 3.50 & & & - & \\
\hline
\end{tabular}

* Significant statistics with the level of 0.05

From table 4, it was found that the different group of reading ability had the different usage of 
vocabulary learning strategies with the significance of 0.05 . In detail, the students who got high scores in reading ability used more vocabulary learning strategies than students who got low scores in reading ability with the significance of 0.05 .

4.3 The result of the vocabulary learning strategies usage of Malaysian high school students who have the different English efficiency

To investigate this research objective, one- way analysis of variance was used as the descriptive statistics, see table 5

Table 5: Result of Malaysian high school students

\begin{tabular}{llllll}
\hline Source of variance & Sum of Squares & df & Mean Square & F & Sig. \\
\hline Between group & 0.50 & 2 & .254 & 3.69 & .04 \\
Within group & 1.45 & 21 & .069 & & \\
Total & 1.96 & 23 & & \\
\hline
\end{tabular}

From the table, it could be explained that the level of reading ability toward vocabulary learning strategies usage of Malaysian high school students who have different English efficiency had the significant statistics with the level of 0.04 . It means that the decision of usage the vocabulary learning strategies followed upon their reading ability. It could be concluded that between the different group of students (High, Medium, and Low) used different vocabulary learning strategies. Then, the Scheffe Method was used to compare each pair difference of the vocabulary learning strategies usage of Malaysian high school students between high, medium, and low group as shown in table 6.

Table 6: Result of Scheffe Method of Malaysian high school students

\begin{tabular}{llllll}
\hline \multirow{2}{*}{ Level } & Mean $(\overline{\mathrm{X}})$ & \multicolumn{3}{c}{ Group } & \multirow{2}{*}{ Sig } \\
\cline { 3 - 5 } & & Low & Medium & High & \\
Low & 3.26 & 3.26 & 2.95 & 2.96 & 0.02 \\
Medium & 2.95 & - & 0.30 & $0.31^{*}$ & \\
High & 2.96 & & - & $0.31^{*}$ & \\
\hline
\end{tabular}

* Significant statistics with the level of 0.05

From table 6, it was found that the different group of reading ability had the different usage of vocabulary learning strategies with the significance of 0.05 . In detail, high reading ability students, medium reading ability students, and low reading ability students used different vocabulary learning strategies. It was found that low reading ability students used more vocabulary learning strategies than high reading ability students and medium reading ability students with the significance of 0.05 .

\section{Conclusion and Recommendation}

This study is an attempt to find the strategies of vocabulary learning used by a group of students 
studying at three Southern Border Provinces of Thailand and border states of Malaysia. The study reveals that most of high reading ability of Thai students used more vocabulary learning strategies than low reading ability group. Meanwhile, most of low reading ability of Malaysian students used more vocabulary learning strategies than the high reading ability group. Two main reasons are discussed about these findings. The first reason is about their good vocabulary skills. These groups of students know well about the vocabulary so it is no need for them to find strategies to know the words. The other reason is about their techniques of using the vocabulary learning strategies. These groups of students could distinguish the effective vocabulary learning strategies so it is no need to use more vocabulary learning strategies. These findings corresponded with the finding of Nosidlak (2013) who studied the vocabulary learning strategies of students from university of Cracow, Poland and found that high reading ability students used less vocabulary learning strategies than low reading ability students. In addition, Nacera (2010) also studied the vocabulary learning strategies by using SILL model with the second year students from Mouloud Mammeri University of Tizi Ouzou, Algeria and found that high reading ability students used more specific vocabulary learning strategies than low reading ability students (Nacera, 2010).

In conclusion, it was evident from the study of Noorizah Mohd. Noor and Zaini Amir (2009) that although low ability students used more vocabulary learning strategies than another group, they needed to continually practice in order to use the effective vocabulary learning strategies. They might have the knowledge of using vocabulary learning strategies, but in practice, they fail. As educators and teachers, we need to understand that learners develop their vocabulary learning over a period of time. Knowing a lot of words does not guarantee that learners are able to read efficiently. Anderson (2008) suggested that there should be a steady study of vocabulary within a reading improvement program. So it was recommended that the most beneficial way to use the vocabulary learning strategies was to continually practice them through various activities (Anderson, 2008).

The learning efficiency couldn't be expected if they couldn't continually practice their knowledge although low reading ability students use more vocabulary learning strategies than the other group. To build the effective strategy among students, more researches are needed to facilitate both language teachers and language learners.

\section{References}

Anderson, N. J. (2008). Practical English Language Teaching: Reading. New York, NY: McGraw-Hill. ASEAN Secretariat. (2014). ASEAN State of Education Report 2013, Public Outreach and Civil Society Division, Jakarta, Indonesia

Azeedad Asgari · and Ghazali bin Mustapha (2011) The Type of Vocabulary Learning Strategies Used by ESL Students in University Putra Malaysia Retrieved online from https://www.researchgate.net/publication/23081349 on 7 September 2015

Bureau of International Cooperation. (2008). Toward a learning society in Thailand. Ministry of Education, Bangkok

Cohen, A. (2011). Strategies in Learning and Using a Second Language (2nd edition). Harlow,UK: Longman.

Cohen, A. D. and Aphek, E. (1980) Retention of second-language vocabulary over time: Investigating the role of mnemonic associations. System, 8(3), 221-235.

Cravern, L. (2013) Vocabulary Learning Strategies. Retrieved online from https://tama.repo.nii.ac.jp/index.php, on 25 February, 2016

Dornyei, Z and Skehan, P. (2003). Individual Differences in Second Language Learning in C.J.Doughty and M.H. Long (eds.) The Handbook of Second Language Acquisition. Oxford: Blackwell 
Fatina Wonglekha. (2010). Preparing Thai students for ASEAN and the globe through English Language Development. Retrieved online from http://social.obec.go.th /node/89, on 20 June 2015

Gu. Y and Johnson, R.K., Vocabulary learning strategies and language learning outcomes, Language Learning, 46(4), 1996, 643-679.

Jensen, M. (2007) Improving Reading Comprehension of Junior Division Students as the Teacher Librarian : An Action Research Study. Master Thesis of Nipissing University, Faculty of Education, North Bay, Ontario, Canada

Kaewklom, S. (2002) Reading Skill Development. Department of Foreign Languages, Faculty of Humanities and Social Sciences, Rajabhat Institute Ubonratchathani

Laufer, B. (2010) Lexical threshold revisited: Lexical text coverage, learners' vocabulary size and reading comprehension. Reading in a Foreign Language, 22 (1) ,15-30

Lawson, J. M. and Hogben, D. (1996). The Vocabulary Learning Strategies of Foreign-Language Students. Language Learning, 46: 1, 101-135.

Macaro, E. (2006). Strategies for language learning and for language use: Revising the theoretical framework. The Modern Language Journal,

Nacera, A. (2010) Language Learning Strategies and the Vocabulary Size. Procedia Social and Behavioral Sciences, 2, 4021 - 4025

Nation, P. (2001). Learning vocabulary in another language. Cambridge: Cambridge University Press.

National Institute of Educational Testing Service. (2014). O-NET Score . Retrieved online from http://www.niets.or.th/th/, on 5 July 2014

Nosidlak K.M.(2013). Vocabulary Learning Strategies of the Advanced Students, Journal of Language Teaching and Research, 4 (4) , 655-661

Noorizah Mohd. Noor and Zaini Amir. (2009) Exploring the Vocabulary Learning Strategies of EFL learners. Retrieved online from https:// www. researchgate.net/ publication/228742158, on 10 October 2015

O’Malley, J.M., Chamot, A. U, Stewner-Manzanares, G, Russo, R., and Kupper, L. (1985) Learning strategy applications with students of English as a second language, TESOL Quarterly 19: 55784

Oxford, R. (1990). Language Learning Strategies. New York, Newbury House Publishers.

Sanaoui, R. (1995). Adult Learners' Approaches to Learning Vocabulary in Second Languages. The Modern Language Journal, 79: i, 15-27.

Schmitt, N. (1997). Vocabulary in Language Teaching. Cambridge. U.K: Cambridge University Press.

Subon, F. (2013) Vocabulary Learning Strategies Employed by Form 6 Students. International Journal of Scientific and Research Publications, $3(6)$

Suknantapong, W., Karnchathat,N. and Kannaovakun, P. (2002) An Analytical Study of Humanities and Social Sciences Students' Problems in Reading English. Songkhlanakarin Journal of Social Sciences and Humanities: 8(2), 121-132

Suphawat Pookcharoen .(2011). Thai EFL Undergraduates' Vocabulary Learning Strategies: Perception and Practice.Journal of English Studies,(6)

Takeuchi, O., Griffiths, C., \& Coyle, D. (2007). Applying strategies: The role of individual, situational, and group differences. Language learner strategies, 69-92). Oxford, UK: Oxford University Press.

Thantawan Kruekaew, Phattrawan Tongkumchum, Chamnein Choonpradub.(2009). Factors Affecting English Vocabulary Skill of Undergraduates At Prince of Songkla University, Pattani Campus. Asian Social Sciences Journal, 4 (9). Retrieved online from ccsenet.org / journal/ index. php/ ass/ 
article / download, on 21 February 2014

Tinutda Komol and Waraporn Sripetpun. (2011) Vocabulary Learning Strategies Employed by Undergraduate Students and its Relationship to their Vocabulary Knowledge. The 3 rd International Conference on Humanities and Social Sciences Faculty of Liberal Arts, Prince of Songkla University Proceedings-Factors Affecting English Language Teaching and Learning 